\title{
INFLUÊNCIA DE BOAS PRÁTICAS DE HIGIENE DE ORDENHA NA QUALIDADE MICROBIOLÓGICA DO LEITE CRU REFRIGERADO
}

\section{Influence of milking good hygiene practices in the microbiological quality of refrigerated raw milk}

\author{
José Carlos Ribeiro Júnior ${ }^{1 *}$, Carolina de Lara Shecaira ${ }^{l}$, Francine Fernandes da Silva , \\ Guadalupe Espicaski Parren ${ }^{I}$, Vanerli Beloti ${ }^{I}$
}

\begin{abstract}
RESUMO
O leite cru produzido por pequenos produtores brasileiros, em geral, apresenta baixa qualidade microbiológica. O objetivo deste trabalho foi verificar o impacto da implantação de boas práticas de higiene de ordenha na qualidade microbiológica do leite cru refrigerado produzido por pequenos produtores no norte do Paraná, Brasil. Foram selecionadas 92 propriedades onde foram realizadas coletas de leite antes e depois do treinamento em boas práticas de higiene na ordenha ("Sequência LIPOA"). Verificou-se que $49(53,3 \%)$ propriedades implantaram total ou parcialmente as boas práticas. Para o total de 92 propriedades, a média de CBT foi de $3,0 \times 10^{6}$ para $1,5 \times 10^{6} \mathrm{UFC} / \mathrm{mL}$ após o treinamento. A média de CCS para essas propriedades se manteve em 2,2 x $10^{5}$ células $/ \mathrm{mL}$. Considerando somente as propriedades que incorporaram as boas práticas de ordenha, a média da CBT reduziu significativamente de $3,8 \times 10^{6}$ para $1,8 \times 10^{5} \mathrm{UFC} / \mathrm{mL}$. A média da CCS foi de $2,2 \times 10^{5} \mathrm{CS} / \mathrm{mL}$ e regrediu para $1,7 \times 10^{5}$ células $/ \mathrm{mL}$ após o treinamento, redução não significativa. Após a adoção das boas práticas de ordenha apenas 3 $(6,1 \%)$ das 49 propriedades continuaram com contagens bacterianas superiores ao padrão de $7,5 \times 10^{5} \mathrm{UFC} / \mathrm{mL}$ estipulado pela legislação. O número de propriedades com CBT igual ou menor que $10^{5} \mathrm{UFC} / \mathrm{mL}$, padrão de qualidade internacional do leite, passou de 13 para 31 após o treinamento. A implantação de boas práticas de higiene na ordenha pode ser o único modo de pequenos produtores alcançarem os padrões de qualidade determinados pela legislação.
\end{abstract}

1 Universidade Estadual de Londrina (UEL), Rodovia Celso Garcia Cid, PR-445, km 380, Campus Universitário, Caixa Postal 10.011, CEP 86057-970, Londrina, Paraná, Brasil. Email: lipoa.uel@ gmail.com

* Autor para correspondência. 
Palavras-chave: contagem bacteriana total; contagem de células somáticas; pequeno produtor.

\begin{abstract}
The refrigerated raw milk produced by Brazilian small producers generally shows low microbiological quality. The aim of the present study was to verify the impact of the milking good hygiene practices implementation on the microbiological quality of refrigerated raw milk produced in small farms in the North of Paraná, Brazil. 92 farms were selected, where milk samples were taken before and after the milking good hygiene practices training, known as "LIPOA". Somatic Cell Count (SCC) and Total Bacterial Count (TBC) analysis were performed by flow cytometry. It was found that $49(53.3 \%)$ farms havefully or partially implemented the good practices. For the total 92 farms, the TBC average went from $3.0 \times 10^{6}$ $\mathrm{CFU} / \mathrm{ml}$ before the training to $1.5 \times 10^{6} \mathrm{CFU} / \mathrm{ml}$ after the training. The SCC average for these farms remained at $2.2 \times 10^{5}$ cells $/ \mathrm{ml}$ after training. Considering only those farms that have incorporated the good practices in milking routine, the TBC average significantly reduced from $3.8 \times 10^{6}$ to $1.8 \times 10^{5} \mathrm{CFU} / \mathrm{ml}$. The SCC average was of $2.2 \times 10^{5}$ that decreased to $1.7 \times 10^{5}$ cells $/ \mathrm{ml}$ after training, a nonsignificant reduction. After the adoption of milking good practices only $3(6.1 \%)$ of the 49 farms continued with bacterial counts higher than the pattern of $7.5 \times 10^{5}$ $\mathrm{CFU} / \mathrm{ml}$ stipulated by the legislation in the analyses occasion. The number of farms with $\mathrm{TBC}$ equal or lower than $10^{5} \mathrm{CFU} / \mathrm{ml}$, that is the international milk quality pattern, increased from $13(26.5 \%)$ to $31(63.3 \%)$ after the good practices training. The milking good hygiene practices implementation can be the only way for small producers to reach the quality patterns determined by the legislation.
\end{abstract}

Keywords: total bacterial count; somatic cell count; small producer.

\section{INTRODUÇÃO}

Diferentemente da Europa, Estados Unidos e outros países, boa parte do leite cru refrigerado brasileiro é oriundo de pequenas unidades produtoras, que apresentam baixos índices zootécnicos (OHI et al., 2010). Segundo dados do Instituto Brasileiro de Geografia e Estatística (IBGE, 2013), há milhões de propriedades produtoras de leite cru no Brasil, sendo a maioria dessas propriedades consideradas como de médio (até de 200 animais) e pequeno porte (até 50 animais), com produtividade média mensal de 1,8 bilhões de litros (julho de 2013).

Estudos preliminares apontam que o grau de tecnificação da produção do leite nas propriedades está diretamente relacionado à qualidade do mesmo (TAFFAREL et al., 2013), portanto, o leite cru produzido por pequenos produtores brasileiros pouco tecnificados apresenta baixa qualidade microbiológica (NERO et al., 2007; BELOTI et al., 2011; RIBEIRO JÚNIOR et al., 2013).

Como consequência disso, a qualidade do leite cru produzido no Brasil ainda é um sério gargalo na produção de derivados lácteos, uma vez que, o leite cru refrigerado deve apresentar qualidade microbiológica boa ou satisfatória a fim de oferecer maior rendimento industrial e gerar derivados nobres (CASTRO et al., 2014). Além disso, 
tal produto ainda proporciona o aumento da lucratividade de indústrias e cooperativas, fato esse que deve beneficiar também ao produtor.

Na tentativa de melhorar a qualidade do leite, o Ministério da Agricultura, Pecuária e Abastecimento do Brasil elaborou a Instrução Normativa 51 (BRASIL, 2002), precursora da Instrução Normativa 62 (BRASIL, 2011) que determinam progressivamente padrões de qualidade mais rígidos para a produção de leite cru. Porém, as precárias condições de produção e a falta de higiene na ordenha fazem com que a qualidade real do leite melhore em um ritmo inferior ao que era previsto pela legislação (OHI et al., 2010).

Portanto, diante da baixa qualidade do leite cru refrigerado produzido por pequenos produtores no Brasil, o objetivo do presente trabalho foi verificar o impacto da implantação de boas práticas de higiene na ordenha na qualidade microbiológica do leite cru refrigerado.

\section{MATERIAL E MÉTODOS}

Foram estudadas 92 propriedades leiteiras da região norte central do estado do Paraná, compreendendo os municípios de Sapopema, Faxinal e Jardim Alegre.

Para o levantamento inicial da qualidade do leite produzido nas propriedades estudadas foram realizadas coletas de amostras de leite antes da implantação das práticas, no período de maio a agosto de 2009. Uma amostra de cada propriedade foi colhida ao final da ordenha diretamente dos tanques de refrigeração ou latões, após homogeneização do leite com a concha de coleta previamente flambada.

Imediatamente após a avaliação inicial da qualidade do leite em cada município, foram realizadas quatro palestras técnicas e quatro treinamentos práticos, ambos coletivos. As práticas de higiene de ordenha indicadas foram descritas por Fagan et al. (2005), chamada

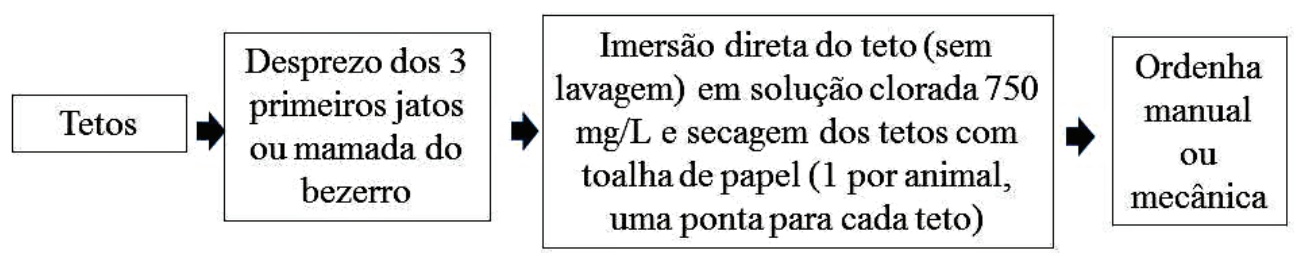

\begin{tabular}{|c|c|}
\cline { 2 - 3 } \multicolumn{1}{c|}{$\begin{array}{c}\text { Baldes, latões } \\
\text { e resfriadores }\end{array}$} & $\begin{array}{c}\text { Pré-enxague; lavagem manual vigorosa com solução de } \\
\text { detergente alcalino clorado } 2 \% \text { e fibra macia (ou bucha vegetal); } \\
\text { deixar agir por } 10 \text { minutos; enxágue; e, inversão dos latões e } \\
\text { baldes para eliminação de água residual. }\end{array}$ \\
\hline
\end{tabular}

\section{Teteiras}

Pré-enxague; lavagem com detergente alcalino clorado $2 \% \mathrm{e}$ escova adequada; enxágue; imersão em solução clorada a 750 $\mathrm{mg} / \mathrm{L}$ por 30 segundos; e, imersão em água para enxágue imediatamente antes da realização da ordenha.

Figura 1 - Esquema da Sequencia LIPOA de boas práticas de higiene de ordenha descrita por Fagan, et al. (2005), modificadas por Matsubara et al. (2011), aplicadas no treinamento aos produtores da região de Sapopema, Faxinal e Jardim Alegre, Paraná, Brasil 
de "Sequencia LIPOA - Laboratório de Inspeção de Produtos de Origem Animal - UEL", modificadas por Matsubara et al. (2011), e estão representadas na Figura 1.

Foram disponibilizados materiais didáticos a cada produtor, cartilhas e folders, que continham todas as informações necessárias para a correta implantação das boas práticas de higiene na ordenha. Cada palestra tinha duração de 1 hora e cada treinamento nas propriedades 1 hora e 30 minutos. Não foi realizado o acompanhamento individualizado de cada produtor integrante do presente trabalho.

Sete meses após o treinamento foram realizadas novas visitas e coletas de leite nas propriedades, no período de março a junho de 2010, para a verificação da implantação das práticas pelos produtores e o impacto destas na qualidade do leite produzido.

As análises foram realizadas no Laboratório de Controle da Qualidade do Leite da Associação Paranaense de Criadores de Bovinos da Raça Holandesa (APCBRH) localizado em Curitiba, Paraná, laboratório oficial da Rede Brasileira de Laboratórios de Controle da Qualidade do Leite no Estado. A coleta e o envio das amostras foram realizados de acordo com o Manual de Operações de Campo do Laboratório, sendo essas amostras analisadas em menos de 24 horas após a coleta.

Para Contagem Bacteriana Total (CBT) foram coletados $40 \mathrm{~mL}$ de leite em frascos específicos com o bacteriostático azidiol para posterior análise por citometria de fluxo (BactoCount - IBC; BentleyInstruments, Chaska, MN, EUA). Em outro frasco, foram coletados outros $40 \mathrm{~mL}$ de leite para Contagem de Células Somáticas (CCS) em frasco com o conservante bronopol e analisados por citometria de fluxo (Somacount $-500^{\circledR}$; BentleyInstruments, Chaska, MN, EUA).

Para análise dos dados os resultados foram convertidos em $\log$ e as médias de CBT e CCS, antes e depois da implantação das práticas, foram comparadas pelo teste $\mathrm{t}$ de Student. Também foi elaborado um gráfico Box Plot para demonstração da distribuição dos resultados e calculados o desvio padrão utilizando o programa STATISTICA versão 7.0 (StatSoft, OK, EUA).

\section{RESULTADOS E DISCUSSÃO}

Durante a segunda visita para coleta de amostras pode-se observar durante a ordenha que das 92 propriedades estudadas 49 $(53,26 \%)$ implantaram as práticas propostas de forma total ou parcial. Por isso, os resultados serão tratados considerando o total de propriedades e em separado aquelas que implantaram as práticas.

Os resultados das contagens bacterianas, antes e depois do treinamento em boas práticas de higiene na ordenha para o total de propriedades e para as propriedades que implantaram as práticas, podem ser observados na Tabela 1 .

Considerando-se a CBT para o total de propriedades pode-se verificar que a média antes da implantação das práticas regrediu significativamente $(\mathrm{p}=0,01)$. Entre as 49 propriedades que implantaram as boas práticas propostas, a redução média foi mais expressiva $(\mathrm{p}=0,0005)$.

$\mathrm{Na}$ ocasião da coleta e obtenção dos resultados, o padrão de CBT era de $7,5 \times 10^{5} \mathrm{UFC} / \mathrm{mL}$, estabelecido pela Instrução Normativa n. 51 (BRASIL, 2002). Considerando esse padrão, $34(37,0 \%)$ do total de propriedades estavam em desacordo, com média de $7,8 \times 10^{6} \mathrm{UFC} / \mathrm{mL}$.

Já no grupo das 49 propriedades que incorporaram as boas práticas de higiene na ordenha, 23 (46,9\%) apresentavam resultado superior ao estabelecido na ocasião de análise para CBT, com média de 7,8 x $10^{6} \mathrm{UFC} / \mathrm{mL}$. A partir da adoção das boas práticas na rotina de ordenha, apenas três $(6,1 \%)$ dessas propriedades continuaram com contagens bacterianas superiores ao padrão. Nesse mesmo grupo, o número de propriedades 
com CBT igual ou menor que $10^{5} \mathrm{UFC} / \mathrm{mL}$ passou de $13(26,5 \%)$ para $31(63,3 \%)$ após o treinamento em boas práticas (Tabela 1).

Matsubara et al. (2011) estudaram quatro propriedades do agreste de Pernambuco, verificando a eficiência das mesmas boas práticas de higiene de ordenha descritas por Fagan et al. (2005) nos pontos de contaminação evidenciados por Silva et al. (2011), através da contagem dos microrganismos indicadores. O percentual de redução das contagens após a implantação de boas práticas variou entre 85,3 e $100 \%$ nos diferentes pontos de contaminação, sendo que a redução média dos microrganismos no pool de leite dos latões foi de 99,9\% para aeróbios mesófilos,
$99,2 \%$ para coliformes totais e $98,0 \%$ para $E$. coli, concluindo que essas práticas são suficientes para a produção de leite que atenda as exigências da legislação.

Vallin et al. (2009) utilizando as mesmas práticas do presente trabalho, acompanharam individualmente 46 propriedades de 19 municípios da região central do $\mathrm{Pa}$ raná e encontram diminuição de $87,90 \%$ da média de CBT. Battaglini et al. (2009) também acompanharam individualmente 111 propriedades da mesma região do presente trabalho e implementaram as mesmas práticas. No seu trabalho, eles comprovaram que a remuneração por qualidade foi determinante para redução da CBT.

Tabela 1 - Intervalo dos resultados da Contagem Bacteriana Total (CBT) do leite do total de 92 propriedades e de 49 que efetivamente implantaram as boas práticas de higiene na ordenha, antes e depois do treinamento em boas práticas, no período de maio de 2009 a julho de 2010 nos municípios de Sapopema, Faxinal e Jardim Alegre, Paraná, Brasil

\begin{tabular}{|c|c|c|c|c|c|}
\hline & \multirow[t]{2}{*}{ Intervalo (x 103/mL) } & \multicolumn{2}{|c|}{ Antes } & \multicolumn{2}{|c|}{ Depois } \\
\hline & & $\mathrm{n}$ & $\%$ & $\mathrm{n}$ & $\%$ \\
\hline \multirow{8}{*}{$\begin{array}{c}\text { Total de } \\
\text { propriedades } \\
(\mathrm{n}=92)\end{array}$} & $1 \vdash 100$ & 29 & 31,52 & 32 & 34,79 \\
\hline & $100 \vdash 200$ & 8 & 8,69 & 9 & 9,77 \\
\hline & $200 \vdash 400$ & 10 & 10,86 & 11 & 11,96 \\
\hline & $400 \vdash 600$ & 8 & 8.70 & 6 & 6,52 \\
\hline & $600 \vdash 800$ & 3 & 3,27 & 7 & 7,61 \\
\hline & $800 \vdash 1000$ & 5 & 5,44 & 3 & 3,27 \\
\hline & $>1000$ & 29 & 31,52 & 24 & 26,08 \\
\hline & Média* & \multicolumn{2}{|c|}{$3,0 \times 10^{6 a}$} & \multicolumn{2}{|c|}{$1,5 \times 10^{6 \mathrm{~b}}$} \\
\hline \multirow{8}{*}{$\begin{array}{l}\text { Propriedades que } \\
\text { implantaram as } \\
\text { práticas }(\mathrm{n}=49)\end{array}$} & $1 \vdash 100$ & 13 & 26,53 & 31 & 63,26 \\
\hline & $100 \vdash 200$ & 4 & 8,16 & 6 & 12,25 \\
\hline & $200+400$ & 3 & 6,12 & 4 & 8,16 \\
\hline & $400+600$ & 5 & 10,20 & 3 & 6,12 \\
\hline & $600 \vdash 800$ & 1 & 2,05 & 2 & 4,08 \\
\hline & $800 \vdash 1000$ & 4 & 8,16 & 3 & 6,12 \\
\hline & $>1000$ & 19 & 38,78 & 0 & 0 \\
\hline & Média* & \multicolumn{2}{|c|}{$3,8 \times 10^{6 a}$} & \multicolumn{2}{|c|}{$1,8 \times 10^{5 b}$} \\
\hline
\end{tabular}

\footnotetext{
* Valores seguidos de letras diferentes na mesma linha diferem entre si $(\mathrm{p}<0,05)$ no teste t de Student $(\alpha=5 \%)$
} 
Na Figura 2 pode ser observada a distribuição dos resultados de CBT do total (92) e das propriedades que incorporaram as boas práticas de higiene na ordenha (49). É possível verificar que a implantação das boas práticas de higiene na ordenha foi capaz de reduzir a distribuição das contagens para o total de propriedades e, expressivamente, para o grupo de propriedades que incorporaram as práticas.

Analisando a qualidade microbiológica do leite produzido pelas propriedades que implantaram as boas práticas de ordenha aqui propostas, pode-se observar que um número expressivo de propriedades apresenta-se de acordo com os padrões internacionais de qualidade dos maiores e melhores produtores mundiais, como se pode observar na Tabela 2 . Já no quesito CCS, pôde-se observar que as médias foram baixas, em torno de $2 \times 10^{5} \mathrm{CS} / \mathrm{mL}$, e para o total de propriedades avaliadas não houve diferença significativa quando se comparou os resultados de CCS antes e depois da implantação de boas práticas de higiene na ordenha (Tabela 3). Foi observado que o número de propriedades com CCS menor que $10^{5}$ células $/ \mathrm{mL}$ aumentou de $33(35,86 \%)$ para $50(54,34 \%)$ após a implantação das práticas de ordenha.

Quando se comparou somente as propriedades que efetivamente incorporaram as boas práticas de ordenha, as médias de CCS diminuíram, mas também não houve variação estatisticamente significativa $(\mathrm{p}=0,11)$ quando se confrontou os resultados antes e depois da implantação das boas práticas na ordenha, apesar da diferença entre as médias ser superior a $4 \times 10^{4}$ células $/ \mathrm{mL}$.

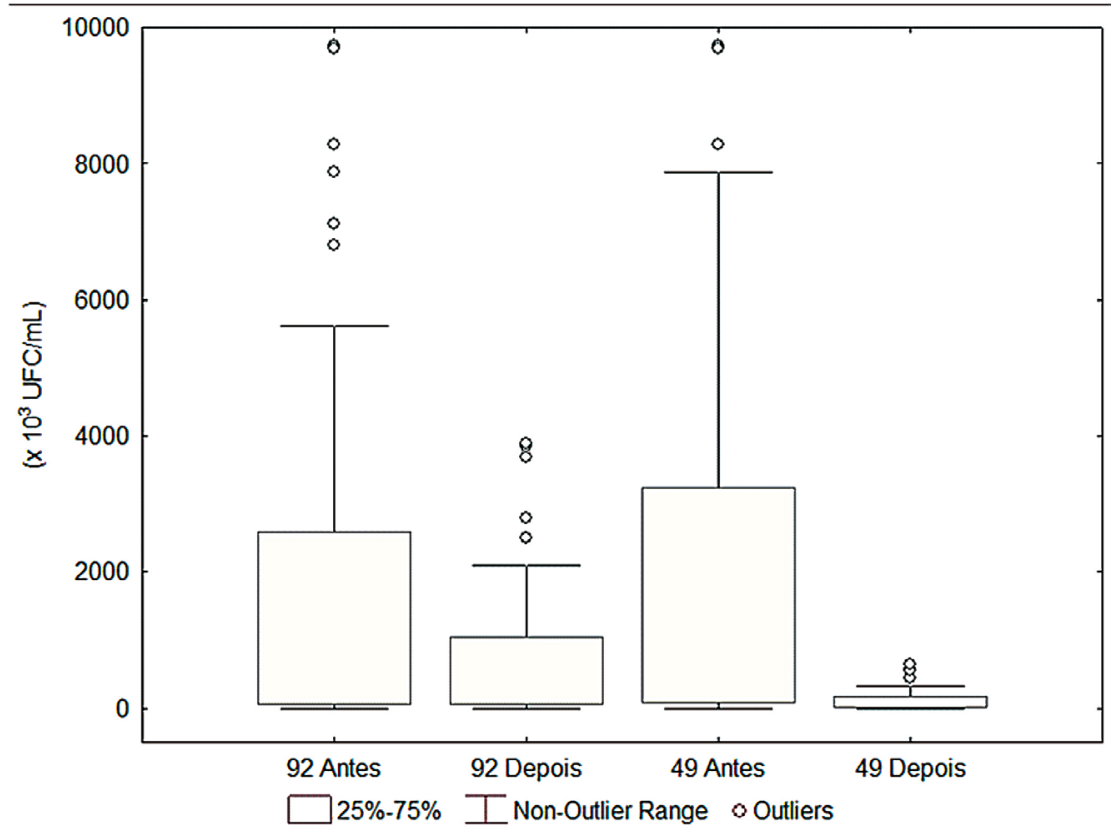

Figura 2 - Distribuição da Contagem Bacteriana Total (CBT) do leite do total de 92 e de 49 propriedades que implantaram boas práticas de higiene na ordenha, antes e depois do treinamento em boas práticas, no período de maio de 2009 a julho de 2010, nos municípios de Sapopema, Faxinal e Jardim Alegre, Paraná, Brasil 


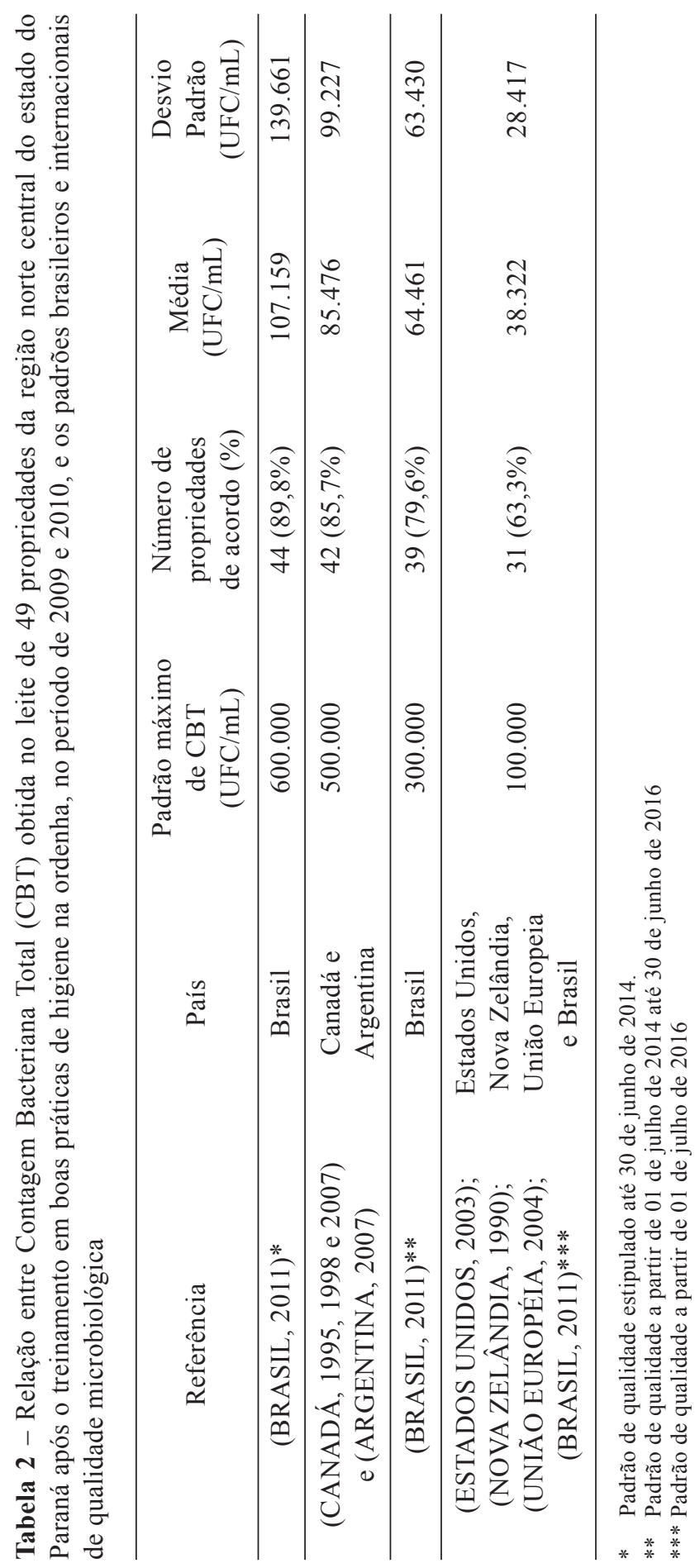


Sabe-se que a resposta da CCS à implantação de boas práticas de higiene na ordenha não é tão imediata e significativa quanto à CBT, uma vez que se faz necessário a adoção de outras práticas específicas, como o manejo dos animais doentes, tratamento das mastites, e às vezes descarte dos animais com mastite recorrente, entre outras, para a redução da CCS (BELOTI et al., 2012). Enquanto que a limpeza e sanitização dos pontos de contaminação microbiológica do leite pré e pós-ordenha é capaz de reduzir a CBT do leite em $98 \%$ já no primeiro dia da implantação das boas práticas (SILVA et al., 2011).

Além disso, como a CCS é indicador da sanidade da glândula mamária, já era esperado que o leite produzido na região apresentasse baixas contagens nesse quesito, uma vez que os animais que compõem o rebanho dessa região são, predominantemente, mestiços e de baixa produção, portanto,com menor frequência de mastite (SANTOS; FONSECA, 2007).

Em suma, as boas práticas de higiene na ordenha propostas foram suficientes para a produção de leite cru refrigerado que atende aos parâmetros de qualidade nacionais e internacionais. A resistência à adoção das boas práticas de ordenha pelos produtores é um entrave à melhoria da qualidade do leite no Brasil, e o pagamento por qualidade poderia acelerar esse processo.

Nas visitas, foram frequentes as queixas de produtores à falta de incentivos pela indústria à produção de leite de melhor qualidade, que seria o pagamento diferenciado. Dessa forma, técnicos, indústrias e órgãos de extensão rural devem atuar diretamente nas unidades produtoras de leite para que seja possível a produção com qualidade que atenda os parâmetros determinados pela legislação, para que a indústria tenha maior lucratividade e remunere melhor os produtores de leite.

\section{CONCLUSÕES}

Um expressivo número de propriedades, que implantaram as boas práticas de ordenha, passou a produzir leite cru refrigerado com padrão de qualidade internacional. Para a melhoria da qualidade do leite cru refrigerado brasileiro serão necessárias medidas de incentivo aos produtores, como programas de pagamento por qualidade do leite, para

Tabela 3 - Contagem de Células Somáticas (CCS) do leite do total de 92 e de 49 propriedades que implantaram boas práticas de higiene na ordenha, antes e depois do treinamento em boas práticas, no período de maio de 2009 a julho de 2010 nos municípios de Sapopema, Faxinal e Jardim Alegre, Paraná, Brasil

\begin{tabular}{|c|c|c|c|c|c|}
\hline & & $\begin{array}{c}\text { Máximo } \\
\left.\text { (x } 10^{6} \mathrm{CS} / \mathrm{mL}\right)\end{array}$ & $\begin{array}{c}\text { Mínimo } \\
\left.\text { (x } 10^{3} \mathrm{CS} / \mathrm{mL}\right)\end{array}$ & $\begin{array}{c}\text { Média* } \\
\left.\text { (x } 10^{5} \mathrm{CS} / \mathrm{mL}\right)\end{array}$ & $\begin{array}{l}\text { Desvio Padrão } \\
\left(\mathrm{x} 10^{5} \mathrm{CS} / \mathrm{mL}\right)\end{array}$ \\
\hline \multirow[b]{2}{*}{ Antes } & Total de propriedades & 1,1 & 8,0 & $2,2^{\mathrm{A}}$ & 2,3 \\
\hline & $\begin{array}{l}\text { Propriedades que } \\
\text { implantaram as práticas }\end{array}$ & 1,1 & 8,0 & $2,2^{\mathrm{a}}$ & 2,5 \\
\hline \multirow[b]{2}{*}{ Depois } & Total de propriedades & 6,9 & 4,0 & $2,2^{\mathrm{A}}$ & 7,5 \\
\hline & $\begin{array}{l}\text { Propriedades que } \\
\text { implantaram as práticas }\end{array}$ & 0,9 & 4,0 & $1,8^{\mathrm{a}}$ & 1,9 \\
\hline
\end{tabular}

* Valores seguidos de letras maiúsculas ou minúsculas iguais na mesma coluna não diferem entre si $(\mathrm{p}>0,05)$ pelo teste t de Student $(\alpha=5 \%)$. 
que os esforços de técnicos, universidades e cooperativas na implantação de boas práticas de higiene na ordenha tenham melhor adesão dos produtores.

\section{REFERÊNCIAS}

ARGENTINA. Secretaria de Politicas, Regulacion y Relaciones Sanitarias - Secretaria de Agricultura, Ganaderia, Pesca y Alimentos. Resolucion Conjunta 112/2007 y 29/2007, 08 ago. 2007. Boletín Oficial, 16 ago. 2007. Disponível em: <http://www.natlaw.com/ interam/ar/fl/rs/prarany00024.pdf $>$. Acesso em: 30 maio 2014.

BATTAGLini A. P. P. et al. Extensão universitária na melhoria da qualidade do leite na região central do Paraná, In: CONGRESO IBEROAMERICANO DE EXTENSIÓN UNIVERSITÁRIA, 10., 2009, Montevidéo. Anais eletrônicos... Montevidéo: ULAM, 2009. Disponível em: <http:// hosting.udlap.mx/sitios/unionlat.extension/ memorias2009/trabajos/sociedad_territorio/ extensao_universitaria_na_melhoria_da qualidade_do_leite_na_regiao_central_do_ parana_brasil.pdf $>$. Acesso em: 05 maio 2014 .

BELOTI, V. et al. Qualidade microbiológica e físico-química do leite cru refrigerado produzido no município de Sapopema/PR.

Revista Científica Eletrônica de Medicina Veterinária, v. 9, n. 16, p. 02-18, 2011.

BELOTI, V. et al. Impacto da implantação de boas práticas de higiene na ordenha na qualidade microbiológica e físico-química do leite cru refrigerado. Revista do Instituto de Laticínios Candido Tostes, v. 67, n. 388, p. 5-10, 2012.

BRASIL. Ministério da Agricultura, Pecuária e Abastecimento. Departamento de Inspeção de Produtos de Origem Animal. Instrução
Normativa $\mathrm{n}^{\mathrm{0}} 51$, de 18 de setembro de 2002. Aprova os Regulamentos Técnicos de Produção, Identidade e Qualidade do Leite tipo A, do Leite tipo B, do Leite tipo C, do Leite Pasteurizado e do Leite Cru Refrigerado e o Regulamento Técnico da Coleta de Leite Cru Refrigerado e seu Transporte a Granel, em conformidade com os Anexos a esta Instrução Normativa. Diário Oficial da República Federativa do Brasil, Brasília, 20 set. 2002. Seção 1, p. 8-13.

BRASIL. Ministério da Agricultura, Pecuária e Abastecimento. Instrução Normativa $n^{\circ}$ 62, de 29 de dezembro de 2011. Aprova o Regulamento Técnico de Produção, Identidade e Qualidade do Leite tipo A, o Regulamento Técnico de Identidade e Qualidade de Leite Cru Refrigerado, o Regulamento Técnico de Identidade e Qualidade de Leite Pasteurizado e o Regulamento Técnico da Coleta de Leite Cru Refrigerado e seu Transporte a Granel, em conformidade com os Anexos desta Instrução Normativa. Diário Oficial da República Federativa do Brasil, Brasília, 30 dez. 2011. Seção 1, p. 6.

CANADÁ. The dairy producers regulations. 1995. Disponível em: <http://www.dairyinfo. gc.ca/pdf/saskdairyproducersregulations. pdf $>$. Acesso em: 30 maio 2014.

CANADÁ. Dairy Industry Acts. 1998. Disponível em: <http://www.dairyinfo.gc.ca/ pdf/peidairyreg.pdf $>$. Acesso em: 30 maio 2014.

CANADÁ. Dairy Industry Acts. 2007. Disponível em: <http://www.qp.gov.ab.ca/ documents/Regs/1999_139.cfm?frm $\mathrm{isbn}=0779712676>$. Acesso em: 30 maio 2014.

CASTRO, K. A. et al. Efeito da contagem de células somáticas sobre a qualidade dos 
queijos prato e mussarela. Revista Brasileira de Tecnologia Agroindustrial, v. 8, n. 1, p. 1237-1250, 2014.

\section{ESTADOS UNIDOS. Grade "A" Pasteurized} Milk Ordinance (2003 Revision): Standards for Grade "A" milk and milk products. Silver Spring: FDA - United States Food and Drugs Administration, Center for Food Safety and Applied Nutrition, Section 7, 2003. Disponível em: <http://www.cfsan. fda.gov/ ear/pmo03-2.html >. Acesso em: 30 maio 2014.

FAGAN, E. D. et al. Avaliação de padrões físico-químicos e microbiológicos do leite em diferentes fases de lactação nas estações do ano em granjas leiteiras no Estado do Paraná - Brasil. Semina: Ciências Agrárias, v. 29, n. 3, p. 651-650, 2008.

INSTITUTO BRASILEIRO DE GEOGRAFIA E ESTATÍSTICA (IBGE). Estatística da produção pecuária em 2013. Disponível em: <http://www.sidra.ibge.gov.br/bda/tabela/ protabl. asp $\mathrm{c}=74 \& \mathrm{z}=\mathrm{t} \& \mathrm{o}=23 \& \mathrm{i}=\mathrm{P}>$. Acesso em: 18 maio 2014.

MATSUBARA M. T. et al. Boas práticas de ordenha para redução da contaminação microbiológica do leite no agreste Pernambucano. Semina: Ciências Agrárias, v. 31, n. 1, p. 277-286, 2011.

NERO, L. A. et al. Resíduos de antibióticos em leite cru de quatro regiões leiteiras no Brasil. Ciência e Tecnologia de Alimentos, v. 27, n. 2, p. 391-393, 2007.

NOVA ZELÂNDIA. Ministry of Agriculture and Forestry. MAF Food: Dairy \& Plants. Circular number 69, Dairy Industry Regulations 1990, D115.1 Raw Milk Acceptance. Wellington, promulgated 19 sep. 2001. Disponível em: <http://www.nzfsa. govt.nz/dairy/publications/standards/d115-1. pdf>. Acesso em: 30 maio 2014.

OHI M. et al. Princípios básicos para a produção de leite bovino. Curitiba: UFPR, 2010. 144p.

RIBEIRO JÚNIOR, J. C. et al. Avaliação da qualidade microbiológica e físico-química do leite cru refrigerado produzido na região de Ivaiporã, Paraná. Revista do Instituto de Laticínios Candido Tostes, v. 68, n. 392, p. 5-11, 2013.

SANTOS, M. V.; FONSECA, L. F. L. Qualidade do leite e controle de mastite. São Paulo: Lemos Editorial, p. 173-178, 2007.

SILVA L. C. C. et al. Rastreamento de fontes da contaminação microbiológica do leite cru durante a ordenha em propriedades leiteiras do Agreste Pernambucano. Semina: Ciências Agrárias, v. 32, n. 1, p. 267-276, 2011.

TAFFAREL, L. E. et al. Contagem bacteriana total do leite em diferentessistemas de ordenha e de resfriamento. Arquivos do Instituto Biológico, v. 80, n. 1, p. 7-11, 2013.

UNIÃO EUROPÉIA. Corrigendum to Regulation (EC) No 853/2004 of the European Parliament and of the Council of 29 April 2004 laying down specific hygiene rules for food of animal origin. Official Journal of the European Union, 29 april 2004. Disponível em: <http://www.fsai.ie/uploadedFiles/Reg 853_2004(1).pdf>. Acesso em: 30 maio 2014.

VALLIN M. V. et al. Melhoria da qualidade do leite a partir da implantação de boas práticas de higiene na ordenha em 19 municípios da região central do Paraná. Semina: Ciências Agrárias, v. 30, n. 1, p. 181-188, 2009. 